\title{
Expression of chemokine receptors in angiosarcoma
}

\author{
Tomoo Kishi1 $^{1,2}$, Yuki Yamamoto ${ }^{1}$, Chikako Kaminaka ${ }^{1}$, Seiko Toyozawa ${ }^{1}$, Hiroshi \\ Matsunaka', Fukumi Furukawa $^{1}$ \\ ${ }^{1}$ Department of Dermatology, Wakayama Medical University, Wakayama, Japan \\ ${ }^{2}$ Department of Dermatology, Kainan Municipal Medical Center, Kainan, Japan
}

\begin{abstract}
Angiosarcoma is a rapidly progressing malignant skin tumor associated with a poor prognosis. We report an immunohistochemical investigation of chemokine receptors in angiosarcoma. The aim is to investigate chemokine receptor expression and, if it is expressed, to histologically discuss its association with age, sex, development site, and histological type. Analyzed were 12 angiosarcoma samples (mean patient age: 75.7 years old) collected by biopsy or surgery from patients at our department by comparing with 4 granuloma telangiectaticum samples (mean patient age: 37.5 years old) and 16 healthy skin samples as controls. CXCR4, CCR6, CCR7, and SDF-1 expressions were immunohistochemically investigated. CXCR4 expression was positive in 6 of the 12 samples. CCR6 and CCR7 were negative in all samples. SDF-1 was positive in 4 samples. Out of the 6 CXCR4-positive samples, 4 were SDF-1-positive. No significant difference associated with age, sex, development site, or histological type was noted in the expression of CXCR4, CCR6, CCR7, or SDF-1. Although CXCR4 is regarded as an index of tumor aggressiveness of malignant melanoma, it is suggested that chemokine receptors, such as CXCR4, do not serve as useful markers of angiosarcoma.
\end{abstract}

Keywords: CXCR4; chemokine receptor; angiosarcoma; immunohistochemistry

Citation: Kishi T, Yamamoto Y, Kaminaka C, Toyozawa S, Matsunaka H, et al. Expression of chemokine receptors in angiosarcoma. J Surg Dermatol 2022; 7(1): 127; http://dx.doi.org/10.18282/jsd.v7.i1.127.

*Correspondence to: Tomoo Kishi, Department of Dermatology, Wakayama Medical University, 811-1 Kimiidera, Wakayama, 641-0012 Japan; tomoo@nnc.or.jp

Received: 15 ${ }^{\text {th }}$ June 2021; Accepted: $1^{\text {st }}$ August 2021; Published Online: 21 ${ }^{\text {st }}$ August 2021

\section{Introduction}

Angiosarcoma is a rare malignant skin tumor appearing as a pink-dark red erythema in the frontal region over the forehead initially and it frequently develops in the elderly. It is accompanied by edema and then forms an erosion, an exudation, and a crust; when it advances, nodules with ulceration occur. It is very malignant, recurring at a local site at a high rate, and causes hemopneumothorax due to lung metastasis in many cases, while also being a disease associated with very poor prognosis $^{[1]}$.
Chemokines are substances inducing the migration of specific white blood cells and lymphocytes, and it has been reported that chemokine and chemokine receptor expressions play important roles in the outgrowth, infiltration, and metastasis of malignant tumors ${ }^{[2-8]}$. Among them, CXCR4 is a specific receptor of the chemokine SDF-1 (CXCL12), and it is expressed on the cell membrane of white blood cells and undifferentiated hematopoietic cells. Its stimulation with SDF-1 induces chemotaxis and promotes proliferation and survival. We previously investigated expressions of CXCR4, CCR6, CCR7, and SDF-1 in malignant melanoma, and reported that CXCR4 is a useful marker and serves as

Copyright (C) 2022 Kishi T, et al. This is an Open Access article distributed under the terms of the Creative Commons Attribution-Non Commercial 4.0 International License (http://creativecommons.org/licenses/by-nc/4.0/), permitting all non-commercial use, distribution, and reproduction in any medium, provided the original work is properly cited. 
an index of malignancy ${ }^{[9]}$. We also reported that expressions of these chemokines may serve as markers of tumor advancement (predicting tumor aggressiveness) of malignant fibrous histiocytoma and dermatofibrosarcoma protuberans $^{[8]}$. Nakatsugawa stated that CXCR4 and SDF-1 expressions on squamous cell carcinoma of the tongue are associated with lymph node metastasis, thus serving as a prognostic factor ${ }^{[10]}$. In reports on tumors other than mucocutaneous tumors, their expressions increased in cases of metastasis of breast and colorectal cancers, suggesting their involvement in tumor metastasis ${ }^{[2]}$.

Analysis of chemokines and chemokine receptors in angiosarcoma has not been performed. Once angiosarcoma develops, it rapidly progresses and results in a poor outcome; however, no useful marker has been identified, and the accumulation of knowledge is urgently needed. In this study, we immunohistochemically investigated chemokine receptors in angiosarcoma, particularly CXCR4, CCR6, CCR7, and SDF-1 (CXCL12).

Using tumor tissue of angiosarcoma, the expressions of CXCR4, CCR6, and CCR7 and a ligand of CXCR4, SDF-1 (CXCL12), were investigated. As clinical control, the expressions in a benign vascular proliferative tumor, granuloma telangiectaticum, were similarly analyzed immunohistologically. Normal control skin samples were also obtained. In addition, the presence or absence of an association with age, sex, development site, and histological type was also investigated.

\section{Materials and methods}

Along with 16 healthy skin samples as controls, 12 angiosarcoma samples (mean patient age: 75.7 years old) and 4 granuloma telangiectaticum samples (mean patient age: 37.5 years old) collected by biopsy or surgery at Wakayama Medical University Hospital's Department of Dermatology, were analyzed. The details of each case are shown in Table 1. The samples were immunohistologically analyzed after obtaining informed consent from the patients and their families. Immunohistochemical staining was performed following the method reported by Toyozawa et al. ${ }^{[8,9]}$. Each sample was fixed with formalin and embedded in paraffin. After deparaffinization, 4- $\mu$ m-thick sections were prepared and subjected to immunohistochemical staining with control, anti-CXCR4 antibody (polyclonal, Gene TEX, Incorporated, San Antonio, TX, USA), anti-CCR6 antibody (polyclonal, Gene TEX), anti-CCR7 antibody (polyclonal, Gene TEX), and anti-SDF-1 antibody (polyclonal, Santa Cruz Biotechnology, Incorporated, Santa Cruz, CA, USA). The expressions were evaluated using the catalyzed signal amplification (CSA) method. For the evaluation, three specialized physicians from Department of Dermatology, who
Table 1. Patient and tumor characteristics

\begin{tabular}{|c|c|c|}
\hline \multicolumn{3}{|l|}{ Patient characteristics } \\
\hline & Angiosarcoma & $\begin{array}{l}\text { Pyogenic } \\
\text { granuloma }\end{array}$ \\
\hline & 12 & 4 \\
\hline \multicolumn{3}{|l|}{ Total number of sites } \\
\hline Median age (years) & 75.7 & 37.5 \\
\hline Range & $61-89$ & $15-54$ \\
\hline \multicolumn{3}{|l|}{ Gender: } \\
\hline Female & 7/12 & $2 / 4$ \\
\hline Male & $5 / 12$ & $2 / 4$ \\
\hline \multicolumn{3}{|l|}{ Location: } \\
\hline Head & $8 / 12$ & $0 / 4$ \\
\hline Face & $3 / 12$ & $3 / 4$ \\
\hline Trunk/neck/extremities & $1 / 12$ & $1 / 4$ \\
\hline Feet & $0 / 12$ & $0 / 4$ \\
\hline \multicolumn{3}{|l|}{ Histopathologic type: } \\
\hline Cellular rich type & $8 / 12$ & $0 / 4$ \\
\hline Vascular rich type & $4 / 12$ & $4 / 4$ \\
\hline \multicolumn{3}{|l|}{ Biopsy/Operation: } \\
\hline Biopsy & $6 / 12$ & $0 / 4$ \\
\hline Operation & $6 / 12$ & $4 / 4$ \\
\hline
\end{tabular}

were unable to access the clinical findings of the patients, randomly selected and observed five visual fields in each section at $400 \mathrm{X}$ magnification ${ }^{[9]}$.

In terms of histological type, the histology tissue section judged as poorly differentiated angiosarcoma was defined as cellular rich type, whereas well-moderately differentiated angiosarcoma was defined as vascular rich type $^{[11]}$.

The correlations of stainability of each antibody with age, sex, development site, and histological type were statistically analyzed using Fisher's exact test.

\section{Ethics statement}

This study was approved by the ethics review board of Wakayama Medical University.

\section{Results}

Immunohistologically investigated were 12 angiosarcoma samples, 4 granuloma telangiectaticum samples, and 16 normal skin control samples.

The results of staining of the normal skin, granuloma telangiectaticum, and angiosarcoma (vascular rich and cellular rich types) are shown in Figures 1-4, respectively.

The results of staining of the normal skin are shown in Figure 1. Figures 1A-1D show staining of CXCR4, CCR6, CCR7, and SDF-1 observed at 200X magnification, respectively. No specific positive reaction with any antibody was observed. Figure 2 shows the results of staining of granuloma telangiectaticum. The hematoxylin and eosin-stained (HE-stained) sample observed at low 
magnification (20X), at a high magnification (400X), and the control are shown in Figures 2A-2C, respectively. The results of CXCR4, CCR6, CCR7, and SDF-1 are shown in Figures 2D-2G, respectively; none of these were stained.

Figure 3A shows the clinical view of an angiosarcoma that developed on the head of a 78-year-old female. Figure 3B shows HE staining of a specimen collected from the lesion shown in Figure 3A, and it was diagnosed as the vascular rich type. Figure $\mathbf{3 C}$ shows the HE-stained sample observed at a high magnification (400X). Figure 3D shows the control. Figure 3E-3H shows the results of CXCR4, CCR6, CCR7, and SDF-1, respectively. CXCR4 and SDF-1 expressions were positive, but CCR6 and CCR7 expressions were negative.

Figure 4A shows the clinical view of an angiosarcoma that developed on the head of a 75-year-old female. Figure 4B shows HE staining of a specimen collected from the lesion shown in Figure 4A, and it was considered to be the cellular rich type. Figure $\mathbf{4 C}$ shows the HE-stained sample observed at a high magnification (400X). Figure 4D shows the control. Figures 4E-4H show the results of CXCR4, CCR6, CCR7, and SDF-1, respectively. CXCR4 expression was positive, but CCR6, CCR7, and SDF-1 expressions were negative.

As shown in Tables 2 and 3, CXCR4 was intensely stained in the cytoplasm or nucleus in 6 of the 12 angiosarcoma samples, being expression-positive. Cellular rich type were determined in 4 of these 6 samples, and 2 were the vascular rich type. CCR6 and CCR7 were negative. SDF-1 expression was positive in 4 of the 12 samples. All these SDF-1 expression-positive cases were also positive for CXCR4 expression. In contrast, all of CXCR4, CCR6, CCR7, and SDF-1 expressions were negative in granuloma telangiectaticum. CXCR4 and SDF-1 expressions are summarized in Tables 2 and 3, respectively. A significant correlation of the presence and absence of expression was noted between CXCR4 and SDF-1. Both CCR6 and CCR7 expressions were negative in all cases. Regarding the association of CXCR4, no significant difference due to age, sex, development site, or histological type was noted. Similarly, no significant difference was noted in CCR6, CCR7, or SDF-1.

\section{Discussion}

Chemokines represent cytokine proteins with chemotactic activity, and their study started in the late 1980s with the discovery of interleukin (IL)-8, a factor inducing neutrophil migration and activation. Subsequently, studies on the molecular pathology of inflammation and immunity have markedly advanced, and more than 50 chemokines have been identified.

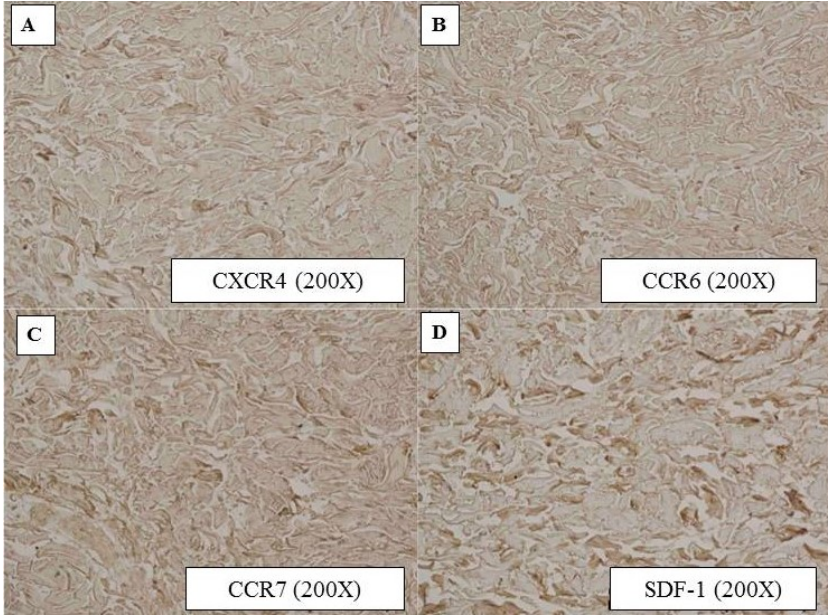

Figure 1. CXCR4, CCR6, CCR7, and SDF-1 immunoexpression in the normal skin (200X). No expression of (A) CXCR4, (B) CCR6, (C) CCR7, and (D) SDF-1 were observed in the normal skin.

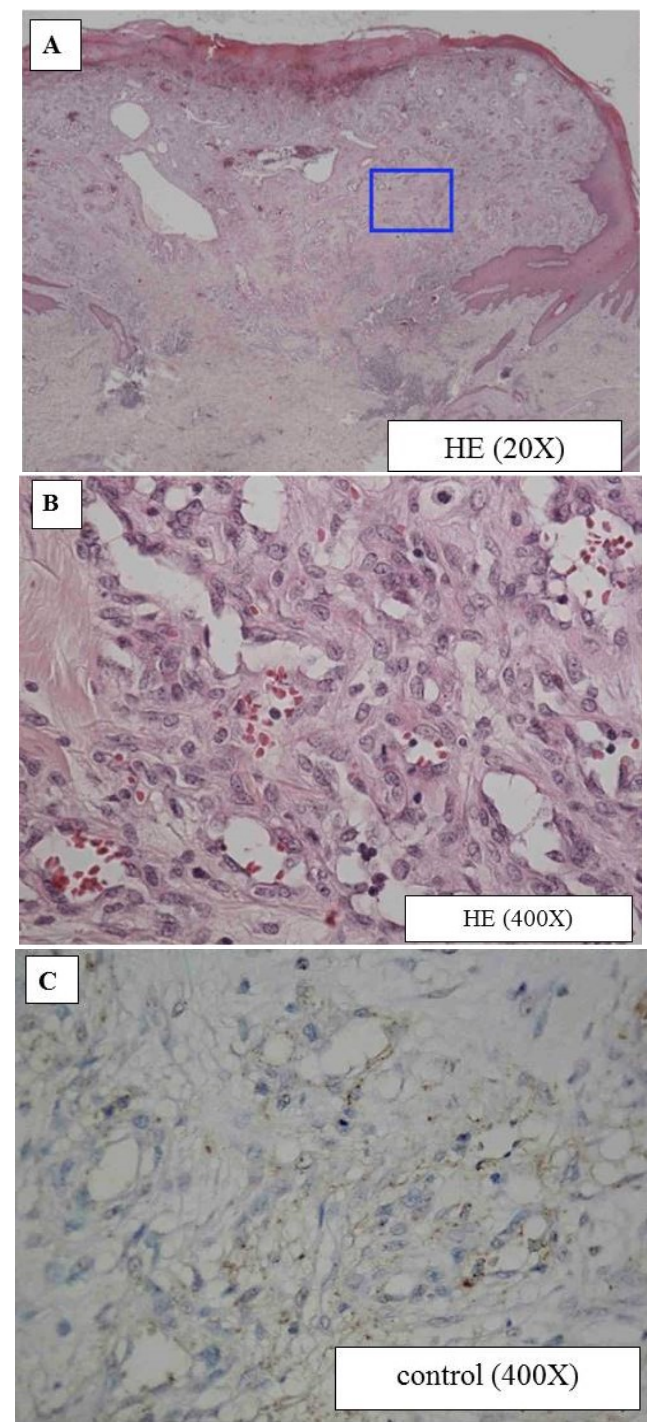




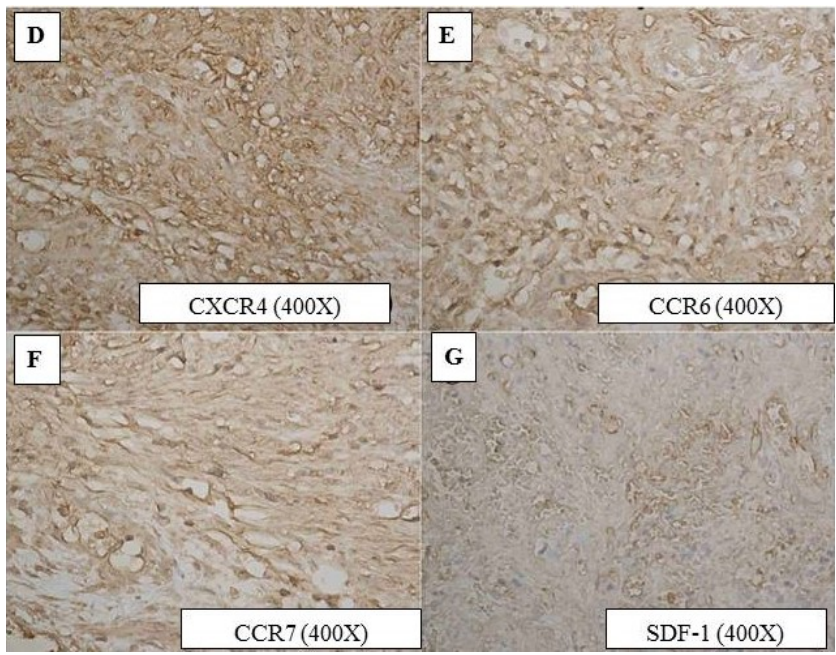

Figure 2. The HE-stained sample of granuloma telangiectaticum under (A) 20X magnification, (B) 400X, and (C) control (400X). No expression of (D) CXCR4, (E) CCR6, (F) CCR7, and (G) SDF-1 were observed in granuloma telangiectaticum.

CXCR4 is a specific receptor of the chemokine SDF-1, and it is expressed on the cell membrane of white blood cells and undifferentiated hematopoietic cells. Its stimulation with SDF-1 induces cancer cell chemotaxis and promotes further proliferation and survival of cancer cells ${ }^{[2]}$. CCR6 is a receptor of CCL20 and it plays an important role in the movement of immunocompetent cells ${ }^{[2]}$. Reduction of CCR6 expression in head-and-neck squamous cell carcinoma has been reported ${ }^{[7]}$. Reportedly, CCR7 is a receptor of CCL19 and CCL21, and it is involved in lymphocyte migration $^{[2]}$; additionally, the enhancement of CCR7 expression in breast cancer, which is likely to metastasize to lymph nodes, has been reported ${ }^{[2]}$. Regarding malignant skin tumors, the involvement of the expression of chemokine receptors such as CXCR4 and CCR7 in tumor growth and metastasis of squamous cell carcinoma, malignant melanoma, and fibrous system malignant tumors has been report$\operatorname{ed}^{[4,5,7,8]}$, but the details of the distribution of expression and function have not been elucidated.

Toyozawa et al. investigated CXCR4, CCR6, CCR7, and SDF-1 expressions in 19 cases of malignant melanoma, and reported that the frequency of CXCR4/SDF-1 expression was significantly higher in the first of the following parameters: a tumor thickness of $2 \mathrm{~mm}$ or less, histological classification of the node or non-node type, and the presence or absence of distant metastasis within two years ${ }^{[9]}$. On the other hand, CCR6 and CCR7 were associated with several parameters but these were not as favorable as markers compared with CXCR4/SDF-1.
Kaminaka et al. histologically investigated the effect of phenol therapy, which is a noninvasive treatment of solar keratosis, Bowen's disease, and squamous cell carcinoma, and they also investigated chemokine receptors immunohistochemically at the same time ${ }^{[12]}$. Compared with normal skin and completely remitted cases, the tumor was thick and CXCR4 was strongly expressed on the first examination, similar to that in squamous cell carcinoma, and they reported that the tumor thickness and CXCR4 expression were associated with the treatment effect.
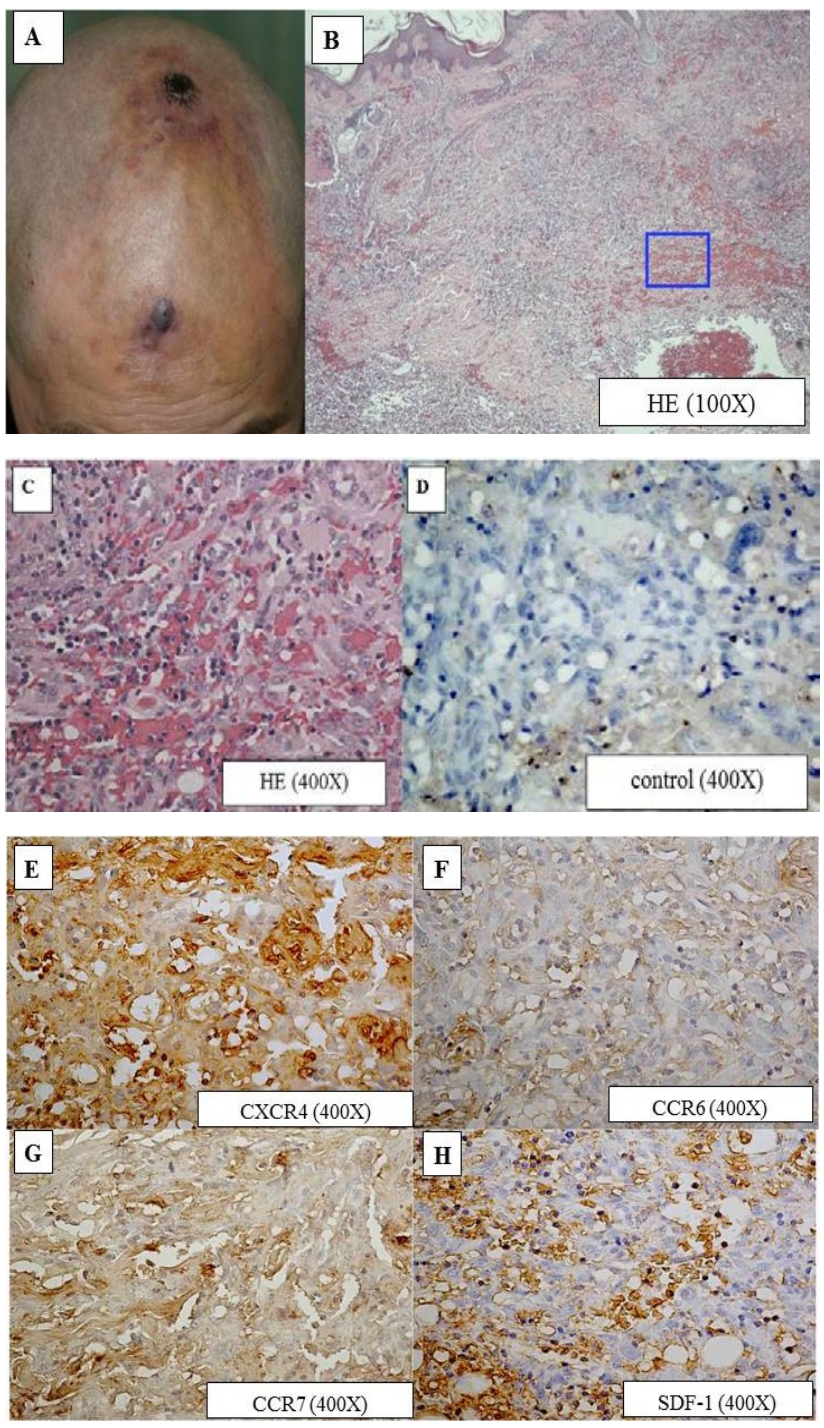

Figure 3. (A) Clinical feature of angiosarcoma in the head of a 78-year-old female. The HE-stained sample of angiosarcoma under (B) 100X magnification, (C) 400X, and (D) control (400X). It was diagnosed as the vascular rich type. The expressions were positive for (E) CXCR4 and (H) SDF-1, but (F) CCR6 and (G) CCR7 expressions were negative. 

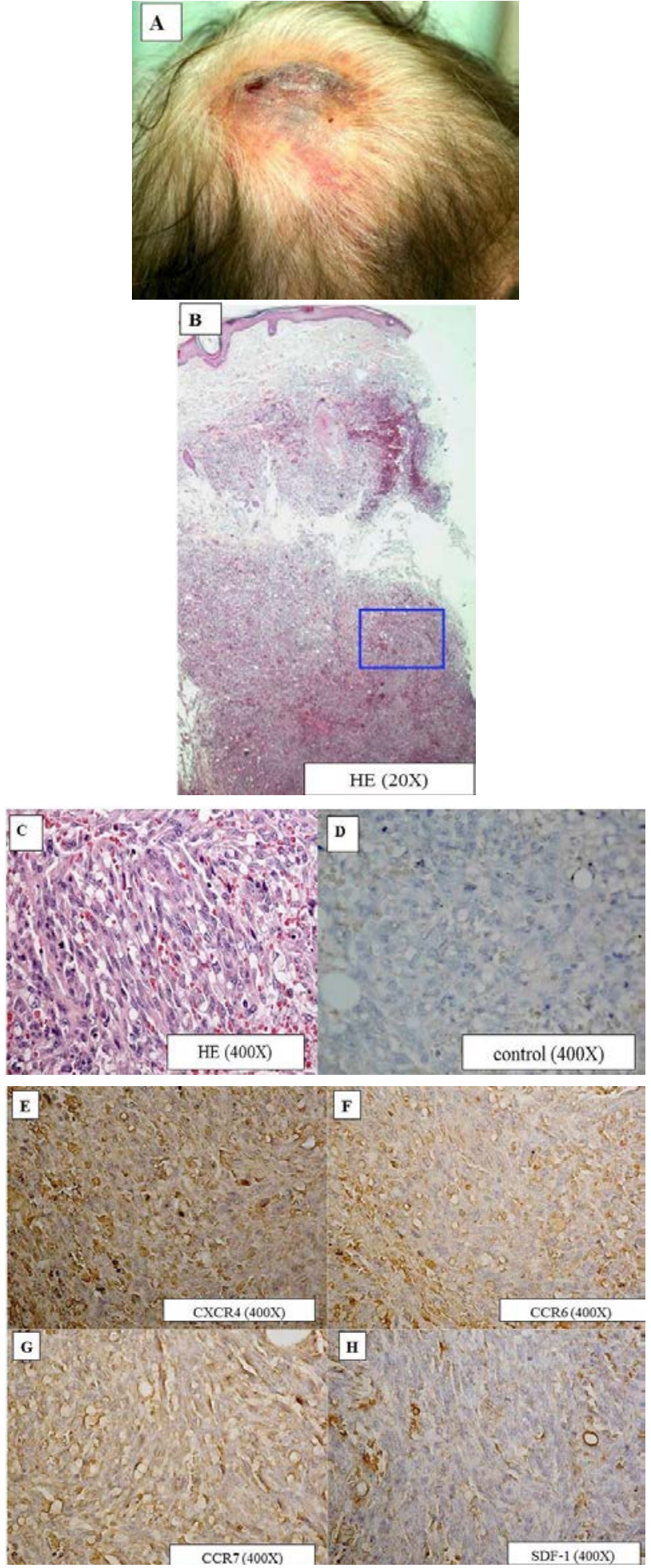

Figure 4. (A) Clinical feature of angiosarcoma in the head of a 75-year-old female. The HE-stained sample of angiosarcoma under (B) 20X magnification, (C) 400X, and (D) control (400X). It was diagnosed as the cellular rich type. The expression of (E) CXCR4 was positive, but (F) CCR6, (G) CCR7, (H) and SDF-1 expressions were negative.
Nakatsugawa investigated CXCR4 and SDF-1 expressions in 53 patients with squamous cell carcinoma of the tongue, in which the frequency of cervical lymph node metastasis was significantly higher in those with SDF-1 gene expression, and the five-year cumulative survival rate was significantly lower in patients with both SDF-1 and CXCR4 gene expressions, than those with no expression of either gene ${ }^{[10]}$. Regarding the other factors, no association of SDF-1 and CXCR4 expressions with any clinicopathological factor was noted during gene analysis or immunohistochemical staining. Nakatsugawa stated that his findings suggest that the association between SDF-1 gene expression and lymph node metastasis of squamous cell carcinoma of the tongue and SDF-1/CXCR4 expression serves as a prognostic factor.

In our study on angiosarcoma, CXCR4 was expressed in half of the cases. CXCR4 was intensely stained in the cytoplasm or nucleus, being positive, in 6 of the 12 samples. Cellular rich type were determined in 4 of these 6 samples, and 2 were the vascular rich type. The association of CXCR4 with age, sex, development site, and histological type was investigated, but no significant difference due to any of these parameters was noted. In addition, CCR6 and CCR7 expressions were negative. SDF-1 expression was positive in 4 of the 12 samples, and all these SDF-1 expression-positive cases were also positive for CXCR4 expression. On the other hand, in granuloma telangiectaticum, which is a representative of benign vascular proliferative disease, CXCR4, CCR6, CCR7, and SDF-1 were negative in all cases.

CXCR4 and SDF-1 expressions were significantly correlated with the clinical views in malignant skin tumors such as malignant melanoma, solar keratosis, Bowen's disease, squamous cell carcinoma, and malignant fibrous histiocytoma; however, no correlation with the clinical view of angiosarcoma was noted. It was hence, suggested that CXCR4, CCR6, CCR7, and SDF-1 do not serve as a useful tumor marker.

Indeed, an investigation of a new chemokine and tumor marker for angiosarcoma is needed.

\section{Conclusion}

In our study on angiosarcoma, CXCR4 was expressed in half of the cases. The association of CXCR4, CCR6, CCR7, and SDF-1 with age, sex, development site, and histological type was investigated; however, no significant difference due to any of these parameters was noted. We have to collect more cases of angiosarcoma and analyze them immunohistochemically. Additionally, we have to investigate the usability of these chemokines as a marker. More development in the study of a new chemokine and tumor marker shall be needed for this disease. 
Table 2. Clinicopathologic features and CXCR4 expression

\begin{tabular}{|c|c|c|c|c|c|}
\hline & & \multirow[t]{2}{*}{$n(\%)$} & \multicolumn{2}{|c|}{$\begin{array}{l}\text { Number of CXCR4 } \\
\text { expression }\end{array}$} & \multirow[t]{2}{*}{$p$} \\
\hline & & & $\begin{array}{r}\text { Positive } \\
\text { n (\%) }\end{array}$ & $\begin{array}{r}\text { Negative } \\
\mathrm{n}(\%)\end{array}$ & \\
\hline \multirow[t]{2}{*}{ Age (years) } & $<70$ & 3/12 (25\%) & $1(33 \%)$ & $2(67 \%)$ & \multirow{2}{*}{1.000} \\
\hline & $\geqslant 70$ & $9 / 12(75 \%)$ & $5(56 \%)$ & $4(44 \%)$ & \\
\hline \multirow[t]{2}{*}{ Gender } & Male & $5 / 12(42 \%)$ & $3(60 \%)$ & $2(40 \%)$ & \multirow{2}{*}{1.000} \\
\hline & Female & $7 / 12(58 \%)$ & $3(43 \%)$ & $4(57 \%)$ & \\
\hline \multirow[t]{4}{*}{ Location } & Head & $8 / 12(67 \%)$ & $4(50 \%)$ & $4(50 \%)$ & \multirow{4}{*}{0.513} \\
\hline & Face & $3 / 12(25 \%)$ & $2(67 \%)$ & $1(33 \%)$ & \\
\hline & Trunk/neck/extremities & $1 / 12(8 \%)$ & $0(0 \%)$ & $1(100 \%)$ & \\
\hline & Feet & $0 / 12(0 \%)$ & $0(0 \%)$ & $0(0 \%)$ & \\
\hline \multirow[t]{2}{*}{ Clinical type } & Cellular rich type & $8 / 12(67 \%)$ & $4(50 \%)$ & $4(50 \%)$ & \multirow[t]{2}{*}{1.000} \\
\hline & Vascular rich type & 4/12 (33\%) & $2(50 \%)$ & $2(50 \%)$ & \\
\hline
\end{tabular}

$* \mathrm{p} \leqslant 0.05$ between groups

Table 3. Clinicopathologic features and SDF-1 expression

\begin{tabular}{|c|c|c|c|c|c|}
\hline & & \multirow{2}{*}{$n(\%)$} & \multicolumn{2}{|c|}{ Number of SDF-1 expression } & \multirow{2}{*}{$p$} \\
\hline & & & Positive n (\%) & Negative n (\%) & \\
\hline \multirow[t]{2}{*}{$\begin{array}{r}\text { Age } \\
\text { (years) }\end{array}$} & $<70$ & $3 / 12(25 \%)$ & $1(33 \%)$ & $2(67 \%)$ & \multirow[t]{2}{*}{1.000} \\
\hline & $\geqslant 70$ & 9/12 (75\%) & $3(33 \%)$ & $6(67 \%)$ & \\
\hline \multirow[t]{2}{*}{ Gender } & Male & $5 / 12(42 \%)$ & $2(40 \%)$ & $3(60 \%)$ & \multirow{2}{*}{1.000} \\
\hline & Female & 7/12 (58\%) & $2(29 \%)$ & $5(71 \%)$ & \\
\hline \multirow[t]{4}{*}{ Location } & Head & 8/12 (67\%) & $2(33 \%)$ & $6(67 \%)$ & \multirow{4}{*}{0.325} \\
\hline & Face & $3 / 12(25 \%)$ & $2(67 \%)$ & $1(33 \%)$ & \\
\hline & Trunk/neck/extremities & $1 / 12(8 \%)$ & $0(0 \%)$ & $1(100 \%)$ & \\
\hline & Feet & $0 / 12(0 \%)$ & $0(0 \%)$ & $0(0 \%)$ & \\
\hline \multirow[t]{2}{*}{$\begin{array}{r}\text { Clinical } \\
\text { type }\end{array}$} & Cellular rich type & 8/12 (67\%) & $2(25 \%)$ & $6(75 \%)$ & \multirow[t]{2}{*}{0.548} \\
\hline & Vascular rich type & 4/12 (33\%) & $2(50 \%)$ & $2(50 \%)$ & \\
\hline
\end{tabular}

$* p \leqslant 0.05$ between groups

\section{Author contributions}

The study was conceived and designed by Kishi T, Yamamoto Y, Kaminaka C, Toyozawa S and Furukawa F. The manuscript was prepared by Kishi T. The statistical analysis was performed by Matsunaka $\mathrm{H}$.

\section{Conflict of interest}

The authors declare no potential conflict of interest with respect to the research, authorship, and/or publication of this article.

\section{References}

1. Griffiths C, Barker J, Bleiker T, Chalmers R, Creamer D (editors). Rook's textbook of dermatology. $9^{\text {th }}$ ed. Oxford, UK: Wiley-Blackwell; 2016. p. 137.36-38.

2. Zlotnik A. Chemokines and cancer. Int J Cancer 2006; 119(9); 2026-2029. doi: 10.1002/ijc.22024.

3. Müller A, Homey B, Soto H, Ge N, Catron D, et al. In- 
volvement of chemokine receptor in breast cancer metastasis. Nature 2001; 410(6824): 50-56. doi: 10.1038/35 065016.

4. Scala S, Ottaiano A, Ascierto PA, Cavalli M, Simeone E, et al. Expression of CXCR4 predicts poor prognosis in patients with malignant melanoma. Clin Cancer Res 2005; 11(5): 1835-1841. doi: 10.1158/1078-0432.CCR-04-18 87.

5. Muller A, Sonkoly E, Eulert C, Gerber PA, Kubitza R, et al. Chemokine receptors in head and neck cancer: Association with metastatic spread and regulation during chemotherapy. Int J Cancer 2006; 118(9): 2147-2157. doi: 10.1002/ijc.21514.

6. Feng LY, Ou ZL, Wu FY, Shen ZZ, Shao ZM. Involvement of a novel chemokine decoy receptor CCX-CKR in breast cancer growth, metastasis and patient survival. Clin Cancer Res 2009; 15(9): 2962-2970. doi: 10.1158/1078-0432.CCR-08-2495.

7. Wang J, Xi L, Hunt JL, Gooding W, Whiteside TL, et al. Expression pattern of chemokine receptor 6 (CCR6) and CCR7 in squamous cell carcinoma of the head and neck identifies a novel metastatic phenotype. Cancer Res 2004; 64(5): 1861-1866. doi: 10.1158/0008-5472.CAN-03-29 68.
8. Toyozawa S, Yamamoto Y, Ishida Y, Kondo T, Nakamura $\mathrm{Y}$, et al. Immunohistochemical analysis of CXCR4 expression in fibrohistiocytic tumors. Acta Histochem Cytochem 2010; 43(2): 45-50. doi: 10.1267/ahc.10003.

9. Toyozawa S, Kaminaka C, Furukawa F, Nakamura Y, Matsunaka $\mathrm{H}$, et al. Chemokine receptor CXCR4 is a novel marker for the progression of cutaneous malignant melanomas. Acta Histochem Cytochem 2012; 45(5): 293-299. doi: 10.1267/ahc.12004.

10. Nakatsugawa S. 舌扁平上皮癌における SDF-1/CXCR4 発現と臨床病理的因子との関連につ い $て$ (Japanese) [On the relationship between SDF-1/CXCR4 expression and clinicopathological factors in squamous cell carcinoma of the tongue]. Dokkyo J Med Sci 2012; 39(1): T1 - T11.

11. Elder DE. In: Elenitsas R, Johnson Jr BL, Murphy GF, $\mathrm{Xu} \mathrm{X}$, (editors). Lever's histopathology of the skin. $10^{\text {th }}$ ed. Philadelphia: Lippincott Williams and Wilkins; 2009. p. 1040-1043.

12. Kaminaka T, Toyozawa S, Yoshi $\mathrm{Y}$, Kunimoto $\mathrm{K}$, Furukawa F, et al. フェノールによる日光角化症とボ 一エン病の治療効果とケモカインレセプターに関す る免疫組織化学的検討 (Japanese) [Phenol peels for the treatment of actinic keratosis and Bowen's disease: Correlation with chemokine receptors expression]. Skin Cancer 2011; 26(3): 327-332. doi: 10.5227/skincanc er.26.327. 